\title{
Pengembangan Bahan Ajar Mikrobiologi Pangan Berbasis Masalah
}

\author{
Sri Rahmadani Harahap ${ }^{1 *}$, Fauziyah Harahap ${ }^{2}$ dan Hasruddin ${ }^{2}$ \\ ${ }^{1}$ SD Negeri 064027 Medan, Kecamatan Medan Polonia, Kelurahan Sari Rejo \\ ${ }^{2}$ Program Studi Pendidikan Biologi Pascasarjana Universitas Negeri Medan \\ *E-mail: sri.rahmadani86@ymail.com
}

\begin{abstract}
The research aims to: (1) Develop a textbook of microbiological food at based problem; (2) determine the response of microbiology lecturer and students to textbooks developed. The textbook was developed to be used as a guide students in conducting lectures learning in the classroom. Data on the quality of development product were collected by questionnaire/questionnaire. Textbook was developed by using a development model Thiagarajan (4-D) that has been modified into a 3-D. The results showed: (1) Validation team of material experts showed an average of $88 \%$ (the excellent category); (2) Validation of the expert team of instructional design showed an average 95\% (excellent category); (3) Ratings lecturer of microbiology showed an average of 92\% (a very interesting category); (4) Trial individuals showed an average $89 \%$ (a very interesting category); (5) Trial small group showed an average of $84 \%$ (a very interesting category); (6) a finite field trial group showed an average of $87 \%$ (a very interesting category).So it can be concluded that product development research microbiology textbooks of based prombles that development is feasible to be used as a textbook students at third semester of Biology Education PPs of Unimed or as supporting lecture material on the material Applied Microbiology in Food Microbiology at Unimed.
\end{abstract}

Keywords: Development of textbooks, Food microbiology, Based problems

\section{PENDAHULUAN}

Proses interaksi terjalin melalui komunikasi, baik langsung maupun tak langsung, lisan atau pun tertulis. Tarigan dalam Haryadi (2003) mengemukakan bahwa buku teks adalah sarana belajar yang biasa digunakan di sekolah-sekolah dan di perguruan tinggi untuk menunjang suatu program pengajaran. Dalam proses komunikasi ini, paling tidak terlibat tiga hal, yakni (a) komunikator: da-lam hal ini penulis sebagai penyampai pesan, (b) komunikan: dalam hal ini pembaca sebagai penerima pesan, dan (c) isi pesan: dalam hal ini konten/konsep disiplin ilmu yang hendak disampaikan.

Mikrobiologi adalah ilmu yang mempelajari tentang mikroorganisme. Mikrobiologi pangan merupakan bagian dalam dari mikrobiologi terapan. Mikrobilogi pangan adalah ilmu yang mempelajari pengaruh proses pengolahan terhadap sel mikroorganisme, termasuk mekanisme ketahanan mikroorganisme terhadap proses pengolahan. Berdasarkan informasi yang diperoleh dari Program Studi Pendidikan Biologi Pascasarjana Unimed, diketahui bahwa proses pembelajaran mikrobiologi terapan dengan materi khusus mikrobiologi pangan yang dilakukan selama ini belum menggunakan buku ajar yang memadai, sehingga hal ini menyebabkan proses pembelajaran sering terjadinya kesalahan dalam memahami materi sehingga memperlama waktu perkuliahan tidak efisien.

Melalui pengembangan buku ajar mikrobiologi pangan berbasis masalah hendaknya dapat memberi masukan pada pendidikan sekarang ini yang diarahkan untuk membekali mahasiswa dengan kecakapan hidup (life skills) yang secara integritas memadukan potensi generic dan spesifik mahasiswa guna memecahkan dan mengatasi problema kehidupan. Hasil yang diharapkan dari penelitian pengembangan ini adalah untuk melihat tingkat efektivitas mahasiswa dalam proses pembelajaran pada mata kuliah mikrobiologi terapan dengan materi mikrobiologi pangan di Program Studi Pendidikan Biologi Pascasarjana Unimed.

Sumardi (2000) mengemukakan buku ajar semestinya disusun berdasarkan pendekatan pembelajaran tertentu sehingga memiliki landasan dan arah yang jelas. 
Ibrahim dan Syaodih (2010) menyatakan bahwa buku ajar akan selalu memegang peranan penting dalam pendidikan karena salah satu rujukan wajib bagi institusi atau sekolah.

Buku ajar dapat dikatakan baik bila memenuhi kriteria sebagai berikut: (1) Menumbuhkan minat pembaca; (2) Ditulis dan dirancang untuk digunakan siswa; (3) Menjelaskan tujuan yang ingin dicapai; (4) Disusun berdasarkan pola belajar yang fleksibel; (5) Strukturnya berdasarkan kompetensi akhir yang dicapai; (6) Berfokus pada kesempatan siswa berlatih; (7) Mengakomodasikan kesukaran belajar siswa; (8) Memberikan rangkuman; (9) Gaya penulisan (bahasanya) komunikatif dan semi formal; (10) Dikemas dalam proses instruksional; (11) Mempunyai mekanisme mengumpulkan umpan balik siswa; dan (12) Mencantumkan petunjuk belajar.

Menurut LTSN (2001) buku ajar berbasis masalah merupakan salah satu bentuk buku ajar yang mengedepankan permasalahan (problem) sebagai konteks dan daya penggerak bagi siswa untuk belajar. Dengan buku ajar berbasis masalah siswa akan memiliki motivasi belajar yang tinggi, membentuk pemahaman mendalam pada setiap pelajaran, dan meningkatnya keterampilan dalam aspek kognitif, problem solving, kerjasama kelompok, komunikas idan berpikir kritis. Sedangkan menurut Ying (2003) buku ajar berbasis masalah mengadopsi ide pokok dalam pembelajaran berbasis masalah atau yag biasa dikenal dengan Problem-based Learning (PBL). Kelebihan dari PBLyaitu siswa sangat antusias dan mempunyai perspektif yang luas tentang pemecahan masalah polusi, termasuk di dalamnya proses kreatif solusi alternatif.

\section{METODE PENELITIAN}

Penelitian ini telah dilakukan di Universitas Negeri Medan (UNIMED), yang terletak di Jl. Wiliam Iskandar Medan Estate pada mahasiswa Program Pascasarjana semester IV. Penelitian ini dilaksanakan pada bulan Februari - Mei 2014/2015.

Penelitian ini merupakan penelitian pengembangan, karena penelitian ini baik untuk mengembangkan buku ajar berbasis masalah. Menurut Sugiyono (2011) bahwa metode penelitian dan pengembangan juga didefinisikan sebagai suatu metode penelitian yang digunakan untuk menghasilkan produk tertentu, dan menguji keefektifan produk tersebut.

Pengembangan perangkat pembelajaran yang disusun dalam penelitian ini mengacu pada jenis pengembangan 4-D karya Thiagarajan yang telah dimodifikasi menjadi 3-D, yaitu Define (pendefinisian), Design (perancangan) dan Development (pengembangan) yang selengkapnya akan disajikan pada Gambar. 


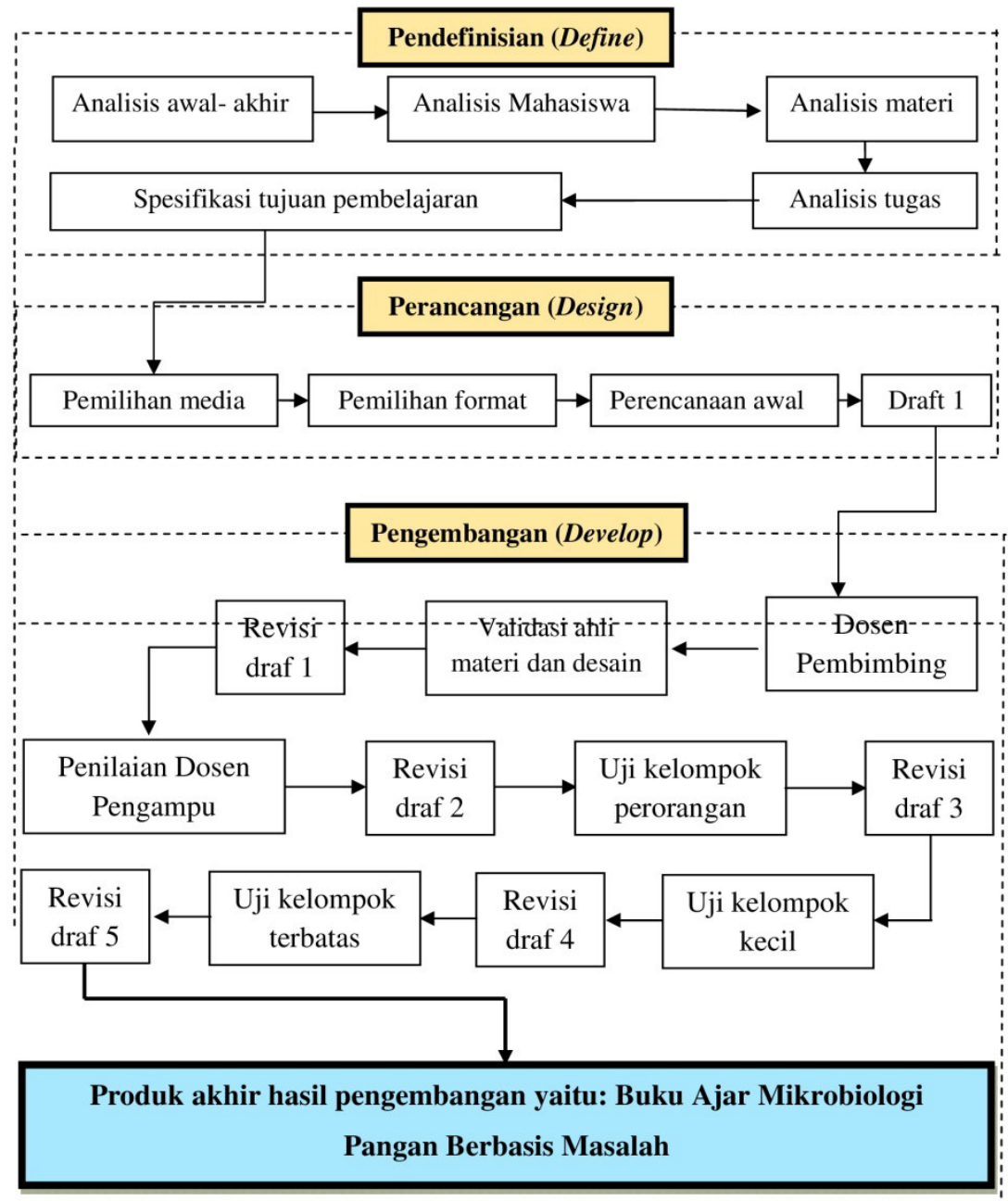

Gambar 3.1. Modifikasi3-D

Uji coba produk dilakukan melalui enam tahap, yaitu validasi oleh tim ahli materi, validasi tim ahli desain, validasi dosen pengampu, uji kelompok perorangan, uji kelompok kecil, dan uji kelompok terbatas. Hal ini dilakukan agar memperoleh data secara lengkap untuk melihat respon dosen dan mahasiswa untuk memperbaiki produk yang dikembangkan. Subjek uji coba ini adalah dosen Mikrobiologi dan mahasiswa semester IV Progran Studi Pendidikan Biologi Pascasarjana Universitas Negeri Medan. Tim ahli materi, tim ahli desain, dan dosen pengampu masing-masing ditunjuk dua orang dosen yang akan memvalidasikan buku ajar yang telah dikembangkan.

Data yang diperoleh disesuaikan dengan tujuan dan desain penelitian dan pengembangan yang digunakan maka jenis data yang dikumpulkan dalam pengembangan ini adalah data deskriptif kualitatif sebagai data pokok, yang terkumpul melalui angket dengan skala penilaian 1 sampai 4 (1: sangat tidak baik/ sangat tidak layak; 2: kurang baik/kurang layak; 3: baik/layak; dan 4: sangat baik/sangat layak).

Data yang diperoleh dalam penelitian ini adalah data kualitatif tentang keadaan buku ajar mikrobiologi pangan berbasis masalah yang telah dikembangkan dimana diperoleh dari penilaian/validasi oleh tim ahli materi, desain dan dosen pengampu mata kuliah mikrobiologi serta lembar angket yang disebarkan kepada mahasiswa. Analisis data hasil penelitian pengembangan ini yaitu, analisis deskriptif dan bukan menguji hipotesa.

\section{Analisis Deskriptif}

Instrumen penelitian untuk validator, uji coba perorangan, kelompok kecil dan uji lapangan terbatas dibuat dalam bentuk skala 
Likert yang telah diberikan skor. dalam bentuk skala Likert seperti yang Layak/tidaknya suatu bahan ajar dapat terlihat pada Tabel berikut:

dilihat dari data angket yang digunakan

Tabel 1. Kriteria jawaban item instrument validasi dengan jenis skala Likert beserta skor dan persentasenya

\begin{tabular}{ccc}
\hline No & Jawaban & Skor \\
\hline 1 & SangatBaik & 4 \\
2 & Baik & 3 \\
3 & KurangBaik & 2 \\
4 & TidakBaik & 1 \\
\hline
\end{tabular}

(Sudjiono, 2007)

Kemudian data dianalisis secara deskriptif kualitatif, yaitu menghitung setiap kategori pada buku ajar yang persentase indicator aspek masalah untuk

Persentase skor berbasis masalah $=\frac{\text { Jumlah indikator per kategori }}{\text { Jumlah indikator total kategori }} \times 100 \%$

(Adisendjadja, 2008)

Klasifikasi skor tersebut selanjutnya diubah menjadi klasifikasi dalam bentuk persentase (Sudjiono, 2007), kemudian

ditafsirkan dalam kalimat bersifat kualitatif yang tercantum dalam Tabel.

Tabel 2. Kriteria persentase kemunculan indicator komponen buku ajar mikrobiologi pangan berbasis masalah yang telah dikembangkan

\begin{tabular}{ccc}
\hline Nilai & Interval Presentase & Kriteria \\
\hline 4 & $81 \% \leq \mathrm{X} \leq 100 \%$ & Sangat Baik \\
3 & $61 \% \leq \mathrm{X} \leq 80 \%$ & Baik \\
2 & $41 \% \leq \mathrm{X} \leq 60 \%$ & Sedang \\
1 & $21 \% \leq \mathrm{X} \leq 40 \%$ & Kurang Baik \\
\hline
\end{tabular}

(Sugiyono, 2011)

Tabel 3. Kriteria persentase kemenarikan buku ajar mikrobiologi pangan berbasis masalah yang telah dikembangkan

\begin{tabular}{ccc}
\hline Nilai & Interval Presentase & Kriteria \\
\hline 4 & $81 \% \leq \mathrm{X} \leq 100 \%$ & Sangat Menarik \\
3 & $61 \% \leq \mathrm{X} \leq 80 \%$ & Menarik \\
2 & $41 \% \leq \mathrm{X} \leq 60 \%$ & Sedang \\
1 & $21 \% \leq \mathrm{X} \leq 40 \%$ & Kurang Menarik \\
\hline
\end{tabular}

(Purwanto yang dikutip dalam tesis Husna 2013)

\section{HASIL PENELITIAN DAN PEMBAHASAN \\ Deskripsi Produk Awal}

Buku ajar yang telah dikembangkan kemudian di validasi oleh tim ahli materi dan tim ahli desain pembelajaran. Tahap ini dilakukan untuk mendapatkan data secara lengkap untuk digunakan sebagai bahan untuk revisi produk yang telah dikembangkan. Selanjutnya, dosen pengampu melakukan penialaian terhadap produk tersebut, lalu dilakukan revisi kedua.

\section{Hasil Validasi Tim Ahli Materi}

Berdasarkan kelayakan isi materi oeh dua ahli materi, bahwa buku ajar mikrobiologi pangan yang dikembangkan 
dinyatakan "sangat baik" dengan jumlah skor total 62 (97\%). Dimana hasil validasi ahli materi pertama yaitu Bapak Prof. Dr. Dwi Suryanto, M.Sc memperoleh jumlah skor 31 (97\%) dengan kategori "sangat baik". Kemudian hasil validasi ahli materi yang kedua yaitu Bapak Ahmad Syafwan S. Pulungan, S.Pd., M.Si memperoleh jumlah skor 31 (97\%) dengan kategori "sangat baik".

Kriteria kelayakan penyajian dinilai "sangat baik" dengan skor total dari kedua ahli materi yaitu 88 (92\%). Dimana hasil validasi ahli materi pertama yaitu Bapak Prof. Dr. Dwi Suryanto, M.Sc memperoleh skor $42(85 \%)$ dengan kategori "sangat baik". Kemudian hasil validasi ahli materi kedua yaitu Bapak Ahmad Syafwan S. Pulungan, S.Pd., M.Si memperoleh skor 46 (96\%) dengan kategori "sangat baik".

Sedangkan kriteria validasi ahli materi terhadap komponen mikrobiologi pangan berada pada katagori "sangat baik" dengan skor total 78 (89\%). Dimana hasil validasi ahli materi pertama yaitu Bapak Prof. Dr. Dwi Suryanto, M.Sc memperoleh skor total 41 (93\%) dengan kategori "sangat baik". Kemudian hasil validasi ahli materi kedua yaitu Bapak Ahmad Syafwan S. Pulungan, S.Pd., M.Si memperoleh skor 37 (84\%) dengan kategori "sangat baik".

\section{Hasil Validasi Tim Ahli Desain Pembelajaran}

Ahli desain pembelajaran memvalidasi produk buku ajar pada aspek desain pembelajaran. Dari hasil validasi buku ajar oleh tim ahli desain pembelajaran disimpulkan bahwa desain buku ajar mikrobiologi pangan yang dikembangkan ini berada pada kategori "sangat baik" dengan jumlah skor total 244 (95\%). Dimana hasil validasi desai pembelajaran pertama memperoleh skor total 121 (95\%) dengan kategori "sangat baik". Kemudian hasil validasi ahli desain pembelajaran kedua memperoleh skor 123 (96\%) dengan kategori "sangat baik".

\section{Hasil Penilaian Buku Ajar Oleh Dosen Pengampu Mikrobiologi}

Dari hasil angket dosen pengampu mikrobiologi terhadap buku ajar mikrobiologi pangan disimpulkan bahwa desain buku ajar mikrobiologi pangan yang dikembangkan ini berada pada kategori "sangat menarik" dengan jumlah skor total 96 (92\%). Dimana hasil dari Bapak Drs. Mhd. Yusuf Nst, M.Si. sebagai dosen pengampu pertama memperoleh jumlah skor 49 (94\%) dengan kategori "sangat menarik". Kemudian hasil dosen pengampu kedua memperoleh jumlah skor 47 (90\%) dengan kategori "sangat menarik".

\section{Hasil Penilaian Buku Ajar pada Uji Coba Perorangan}

Buku ajar mikrobiologi pangan yang telah divalidasi oleh tim ahli materi, tim ahli desain pembelajaran dan dinilai oleh dosen pengampu, kemudian dilakukan uji coba perorangan. Uji coba perorangan dilakukan terhadap tiga orang mahasiswa untuk mengidentifikasi kekurangan produk dan presepsi awal mahasiswa terhadap produk yang dikembangkan. Data hasil angket presepsi terhadap buku ajar pada uji coba perorangan dapat disimpulkan bahwa buku ajar mikrobiologi pangan berbasis masalah yang dikembangkan berada pada kriteria "sangat menarik" dengan skor total 169 (89\%).

\section{Hasil Penilaian Buku Ajar pada Uji Coba Kelompok Kecil}

Uji coba kelompok kecil dilakukan terhadap sembilan orang mahasiswa untuk mengidentifikasi kekurangan produk dan presepsi awal mahasiswa terhadap produk yang dikembangkan. Data hasil angket presepsi terhadap buku ajar pada uji coba kelompok kecil dapat disimpulkan bahwa buku ajar mikrobiologi pangan berbasis masalah yang dikembangkan berada pada kriteria "sangat menarik" dengan skor total $456(84 \%)$.

\section{Hasil Penilaian Buku Ajar pada Uji} Coba Kelompok Lapangan Terbatas

Uji coba kelompok lapangan terbatas dilakukan terhadap 30 (tiga puluh) orang mahasiswa untuk mengidentifikasi kekurangan produk dan presepsi awal 
mahasiswa terhadap produk yang dikembangkan. Data hasil angket presepsi terhadap buku ajar pada uji coba kelompok lapangan terbatas dapat disimpulkan bahwa buku ajar mikrobiologi pangan berbasis masalah yang dikembangkan berada pada kriteria "sangat menarik" dengan skor total 1567 (87\%).

\section{KESIMPULAN}

Berdasarkan hasil temuan yang telah diuraikan pada kesimpulan hasil penelitian, berikut ini diajukan beberapa saran, yaitu (1) Buku ajar mikrobiologi pangan ini disusun berdasarkan kebutuhan mahasiswa dan juga melalui pengujian oleh para ahli. Oleh karena itu buku ajar mikrobiologi pangan ini dapat dicetak dan dipergunakan sebagai buku pedoman dalam proses kegiatan pembelajaran, (2) untuk pemahaman yang lebih mendalam lagi perlu dikembangkan produk buku teks mikrobiologi pangan sebagai pedoman di dalam kelas, dan (3) untuk mengetahui perkembangan lebih lanjut dari produk bahan ajar ini perlu dilakukan penerapan dalam proses pembelajaran di dalam kelas dan melibatkan dosen/instruktur sebagai fasilitator dalam penyampaian materi dalam buku tersebut.

\section{DAFTAR PUSTAKA}

Adisendjaja, Y.H. dan Romlah. 2008. Analisis Buku Ajar Sain Berdasarkan Literasi Ilmiah Sebagai Dasar Untuk Memilih Buku Ajar Sains (Biologi). Bandung: FMIPA Universitas Pendidikan Indonesia.

Depdiknas. 2008. Panduan Pengembangan Bahan Ajar. Jakarta: Depdiknas Direktorat Jenderal Manajemen Pendidikan Dasar dan Menengah Direktorat Pembinaan SMA.

Forgaty, R. (1997). Problem-Based Learning and Other Curriculum Models for the Multiple Intellegences Classroom. Australia: Hawker Brownlow Education.

Haryadi. 2003. "Hubungan Intensitas Mendengarkan Ceramah, Pemahaman Buku Teks dan Partisipasi Berorganisasi dengan
Retorika”. Jurnal Kependidikan Nomor 2 Tahun XXXIII, November 2003.

LTSN. 2001. Problem-based Learning:an Introduction.Primer 4, version 1. [Online].http://ltsn-psc@ @ul.Ac.uk. [Diakses 19 Mei 2014]. SEMNAS MIPA III UNDIKSHA.

Mahardika, I. Ketut. 2011. Bab II Kajian Teori Pengembangan Bahan Ajar. Universitas Prndidikan Indonesia. [Online]. http://repository.upi.edu/8468/2/d_ipa_0809 632_table_of_content.pdf. [Diakses 11 April 2013].

Sinambelan, Pardomuan, N.J.M. 2009. Keefektifan Model Pembelajaran Berdasarkan Masalah (Problem-Based Instruction) Dalam Pembelajaran Matematika.[Online]. https://pardomuansinambela.files.wordpress. com/2009/12/artikel-sinambela.pdf. [Diakses 10 Mei 2014].

Sugiyono. 2011. Metode Penelitian Kuantitatif Kualitatif dan $R \& D$. Bandung.Alfabeta.

Sukmadinata, N. S. 2009. Metode Penelitian Pendidikan. Bandung: Rosda Karya.

Suryadi, D. 2005. Penggunaan Pendekatan Pembelajaran Tidak Langsung serta Pendekatan Gabungan Langsung dan Tidak Langsung dalam Rangka Meningkatkan Kemampuan Berpikir Matematik Tingkat Tinggi Siswa SLTP. Bandung: Disertasi SPs UPI.

Trianto. 2007. Model-Model Pembelajaran Inovatif Berorientasi Konstruktivistik, Jakarta: Prestasi Pustaka.

Trianto. 2009. Mendesain Model Pembelajaran Inovatif-Progresif: Konsep, Landasan, dan Implementasinya pada Kurikulum Tingkat Satuan Pendidikan (KTSP). Jakarta

Trianto. 2011. Model Pembelajaran Terpadu: Konsep, Strategi, dan Implementasinya dalam Kurikulum Tingkat Satuan Pendidikan (KTSP). Jakarta: Bumi Aksara.

Umaedi. 2002. Manajemen Peningkatan Mutu Berbasis Sekolah: Buku 5 Pembelajaran dan Pengajaran Kontekstual. Jakarta : Depdiknas.

Takwim, Bagus. 2006. Mengajar Anak Berpikir Kritis. [Online]. http://www.kompas.-com/kesehatan/news/0605/05/093521.htm. [Diakses 21 Juni 2014] 